\title{
Developing A Resilience-Based Adaptive Co-Management Framework: Public Sectors' Insights on the Role of Tourism
}

\author{
Ignatius P. Cahyanto, Bingjie Liu-Lastres, \& Chase Edwards
}

\begin{abstract}
Public-private partnerships are essential to effective disaster response and recovery. As important as it is to address the governments' continuous effort, a community's resilience can also be enhanced by leveraging private entities and their involvement. This study utilized the Adaptive co-management (ACM) framework to examine existing partnerships between emergency operations centers and the tourism industry in co-managing hurricane-related disasters. By utilizing group discussion and individual interviews, this study reveals the public sectors' expectations of the tourism industry when partnering to co-manage disasters. The findings highlight theoretical and practical implications for current public-private partnerships and the need to improve these efforts in disaster management. Several critical deficiencies are identified and discussed, including interagency trust, financial support, and communication.
\end{abstract}

Keywords: co-management; destination resilience; hurricane; public-private; tourism policy

\section{Introduction}

Among the most critical issues faced by destinations is the need to increase community resilience to disasters and effectively respond to and recover from disasters. The number of disaster declarations in the U.S. has increased dramatically over the past decade, with 65 major declarations per year on average and a total of 1,907 declarations from 2000 to 2014 (Department of Homeland Security [DHS], 2018). Of the myriad catastrophes in

This is the author's manuscript of the work published in final edited form as:

Cahyanto, I. P., Liu-Lastres, B., \& Edwards, C. (2021). Developing a resilience-based adaptive co-management framework: Public sectors' insights on the role of tourism. Journal of Policy Research in Tourism, Leisure and Events, 13(2), 204-221.

https://doi.org/10.1080/19407963.2020.1759611 
the U.S., hurricanes have caused the most damage. For example, damage from Hurricane Katrina is appraised at \$160 billion, surpassing Hurricane Harvey’s \$125 billion in losses. The average cost of hurricane damage is estimated at $\$ 21.6$ billion (Frohlich, 2018).

Traditionally, the primary responsibility for managing disasters has rested with the public sector. Examples of the key players in the public sector include federal agencies such as the Department of Homeland Security (DHS), U.S. Department of Housing and Urban Development (HUD), and the U.S. Department of Health and Human Services (HHS), as well as state and local agencies including government and Emergency Operations Centers (EOC). Despite the involvement of these parties, hurricane studies consistently highlight the need for the public sector to develop more effective procedures that can be mobilized to cope with large-scale disasters (Kapucu, 2006; Mitchell, 2006; Chen et al., 2013; Gabler, Richey, \& Stewart, 2017). Kofinas (2009) also stressed the importance of a flexible approach that results in collaboration between the public and private sectors. There is growing widespread recognition that a cross-sector approach is essential in preparing for, responding to, and recovering from catastrophic disasters and fostering prolonged community resilience (Chandra, Moen, \& Sellers, 2016; Ritchie \& Campiranon, 2015).

Many private entities, ranging from hotels, hospitals, to debris removal contractors, are actively involved in disaster response and recovery. One key partner in responding to disasters is the tourism industry (Nguyen, Imamura, \& Iuchi, 2017). The tourism industry covers multiple sectors, including accommodation, food and beverage, and destination management, all of which frequently provide much-needed services to first responders, evacuees, and other local businesses and organizations within their communities during disasters. For instance, following the onset of a hurricane, hotel 
rooms can be used as shelters or temporary housing for firefighters and routinely function as alternative EOCs. The accommodation sector also routinely provides alternative shelters for evacuees who are unable to return home for an extended period of time post-disaster.

Furthermore, destination management organizations (DMO) have the responsibility to ensure visitor safety and provide the public with accurate risk and crisis information, both of which align well with the scope of disaster management. Therefore, they also undertake the role of information providers and destination marketers as part of response and recovery efforts (Cahyanto \& Pennington-Gray, 2015; Cahyanto et al., 2014). Recognizing its increasing involvement and importance, studies recommend that the tourism industry should foster working relationships with local EOCs to safeguard the needs of the industry and visitors during disasters (Jiang \& Ritchie, 2017; Ritchie, 2004; Cahyanto et al., 2014).

Despite the importance of establishing a public-private partnership in disaster management, most existing studies have been from the vantage point of the tourism industry's perspective, reporting their experience of working with the public sector and developing strategies to foster partnerships with the public sector to safeguard the industry (Jiang \& Ritchie, 2017). Very few of these studies have explored the public sector's perceptions and concerns over the public-private partnership in a disaster management context. Accordingly, the purpose of this study was to examine the public sector's view on their disaster-related partnerships with the tourism industry, the nature of such partnerships, and the challenges. 


\section{Literature Review}

\subsection{Guiding Theory: Adaptive Co-Management}

Singleton (1998) referred to co-management as a system of governance that combines state control with local, decentralized decision-making and accountability, which enhances the strengths and mitigates the weakness of each individual entity. The World Bank (1999) defined co-management as the sharing of responsibilities, rights, and duties between the principal stakeholders, specifically local communities and the state. Berkes (2009) defined co-management as the sharing of power and responsibility between governments, users of resources, and the partnerships involved. In co-management, various actors discuss, express, and provide reassurance to each other during the equitable management of functions, rights, and responsibilities for a given resource (Borrini-Feyerabend et al., 2000). While there is no single unanimously accepted definition of co-management, it is generally agreed that co-management is comprised of partnerships and cooperative governance agreements involving multiple actors (Armitage, Berkes, \& Doubleday, 2007; Berkes, 2002; Plummer \& Fitzgibbon, 2004). Specifically, partnership in co-management can be viewed as a continuum ranging from simple information exchange to formal partnerships (Carlsson \& Berkes, 2005).

Plummer and Fitzgibbon (2004) highlighted the empirical nature of co-management, suggesting that it is 'a blending of both practice and theory (p. 876).'

Carlsson and Berkes (2005) posited that co-management involves the following elements: 1) management of resources; 2) some type of partnership between the public and private actors; 3 ) the partnership is not a fixed state but is instead a process that occurs along a continuum. Indeed, co-management has exerted a profound impact on resource management, and recent efforts have incorporated the concepts of resilience and well-being as well as integrated ecology, economy, and society (Plummer \& 
Armitage, 2007). Within the tourism literature, co-management refers to sharing in the management of natural resources or protected areas through connecting stakeholders at multiple levels (Berkes, 2007, 2009; Borrini-Feyerabend, 1996; Islam, Ruhanen, \& Ritchie, 2017, 2018, 2019; Jaireth \& Borrini, (2007). Co-management of resources in tourism destinations is a pivotal issue in the application of environmental sustainability and appropriate economic development (Halim, 2016; Berkes, George, \& Preston, 1991; Graci, 2013; Shoeb-Ur-Rahman et al., 2019).

The concept of adaptive co-management (ACM) was then introduced to tourism literature. It extends the co-management approach by incorporating adaptive management and aims to enhance and sustain natural resources and improve the socioecological resilience of the system (Islam et al., 2017, Plummer \& Armitage, 2007). There are four principles of ACM: 1) Communication and collaboration among stakeholders, which leads to higher interaction, participation, and partnership among stakeholders, 2) Social learning, in which stakeholders work and learn together to manage the resource, and engage in interactive learning through collaboration, 3) Shared rights, responsibility and decision making, which allows for power-sharing and conflict resolution among stakeholders, and 4) Building adaptive capacity and resilience, which aims at improving local communities' adaptive capacity and resilience (Islam et al., 2017). Guided by the ACM approach, Islam et al. (2019) studied two protected areas in Bangladesh and found that well execution of the ACM principles could result in increased participation from various stakeholders in co-managing a destination.

The application of ACM has also been extended to tourism crisis management. Co-management is often necessitated by certain pre-conditions in the external environment (Mitchell, 1997; Pinkerton, 1989; Selin \& Chavez, 1995). When disasters 
occur, people typically collaborate to solve the issues, and the solutions often result in some change. In this sense, a disaster serves as a critical pre-condition for comanagement success, increasing the likelihood that stakeholders will deem comanagement networking to be feasible and expedient. Pennington-Gray, Schroeder, and Gale (2014) argued five key characteristics that are essential for tourism crisis management based on ACM. They are 1) pluralism, 2) communication, 3) transactive decision-making, 4) social learning, and 5) shared action. Pluralism involves the inclusion of multiple interests and stakeholders (Stankey, McCool, Clark, \& Brown, 1999). Communication refers to the information exchange between all key stakeholders. Transactive decision-making in disaster response and management requires public and private agencies to reach a consensus or a shared understanding and stipulates that all parties work together in a unified manner (Gray, 1989; Wondelleck \& Yaffee, 2000). Social learning denotes the mutual knowledge gained by stakeholders through shared values, strategies, actions, and feedback (Selin \& Chavez, 1995; Woodolleck \& Yaffee, 2000). Lastly, shared action is described as a joint response by all actors involved in disaster management (Berkes, 1997; Ingels, Musch, \& Qwist-Hoffman, 1999;

Wondolleck \& Yaffee, 2000). Given its suitability to tourism crisis management, ACM was used as the guiding theoretical framework of this study.

\subsection{Public-Private Partnership in Tourism Crisis Management}

A public-private partnership (PPP) refers to the collaboration between public and private sectors in working towards shared objectives through a mutually agreed-upon division of labor and by committing resources and sharing risks and benefits (Buse, Kent, \& Walt, 2000). A partnership can be based on formal or informal arrangements made prior to the disasters as well as impromptu activities that ensue during a disaster. Interest in PPPs has grown dramatically in disaster management over the last decade 
(Boyer, 2019; Chen et al., 2013) because the fragmented social responsibility for developing and implementing disaster policies requires the use of partnership mechanisms (May \& Williams, 1998). While there is a broad consensus that governments must assume a leadership role in disaster management, it has become obvious that government agencies are lacking sufficient resources and capabilities. Correspondingly, partnerships have emerged as a response to a broader trend that envisions a smaller role for the public sector in disaster response (Curnin \& O’Hara, 2019; Christoplos, 2003).

In areas in which disaster response activity has traditionally been performed by public agencies, arrangements between governments and private sectors have recently been embraced by a wide range of communities and is increasingly seen as the solution to government problems and needs in an era of scarce public resources (Curnin \& O’Hara, 2019; Chen et al., 2013). The trend to share responsibilities by governments with private sectors reflects a variety of motives and beliefs. There is currently a robust debate about the actual success and feasibility of PPPs in disaster management (Hayllar \& Wettenhall, 2010; Siemiatycki, 2011; Chen et al., 2013). Some studies suggest that PPPs can boost production, increase quality and efficiency, provide access to new financial resources, and reduce exposure to risks (RECIPE, 2011) by reconstituting the role of the state in governing and regulating competitive market processes (Siemiatycki, 2011). Others argue that the benefits of public-private partnerships are exaggerated, and their consequences are disproportionately distributed (Van den Hurk \& Siemiatycki, 2018; Siemiatycki, 2011, Warner, 2006). Hayllar and Wettenhall (2010) posited that these partnerships are often damaging to the public interest. Nonetheless, there is an increasing number of cases of successful partnerships in disaster management contexts worldwide (Lee, Watanabe, \& Li, 2019; Bajracharya, Hastings, Childs, \& McNamee, 
2012, NRC, 2011; UNISDR, 2008). There is also consensus that PPP is critical for preparing for, responding to, and recovering from large scale disasters (NRC, 2011).

In the same vein, the tourism industry is familiar with the concept of PPP, which has been used as a strategy in response to the changes in tourism demand as well as the increasing need for recreation and exceptional tourism experiences (Wilson, Nielson, \& Buultjens, 2009). PPPs have been applied in various tourism contexts, such as national parks and protected-area management (Wilson et al., 2009), tourism policies, and tourism planning (Bramwell \& Sharman, 2000) and sustainable tourism development (De Lacy et al., 2002). Consistent with the scope of adaptive co-management, these studies repeatedly address the importance of collaboration and partnerships among key

stakeholders. When it comes to tourism crisis management, Pennington-Gray et al. (2014) developed and tested a tourism area response model that is based upon the adaptive co-management theory, however, while focusing on responding to a crisis in destinations, it did not take a holistic approach that considers community resilience. Despite this attempt, the role of adaptive co-management, as well as the PPPs in tourism crisis management, has not been explicitly examined.

\subsection{Co-Managing Disasters by Emergency Operations Centers and the Tourism Industry}

EOCs which were formed as part of the United States Civil Defense, are one of the key public agents in disaster management (FEMA-EMI, 2010). EOCs are now part of all levels of government and act as the central command and control facility for disaster planning, response, and recovery (FEMA, 2011). EOCs are essential as many disaster situations require responses that may overwhelm the resources of individual departments, agencies, or the communities. Additionally, centralized coordination through an EOC can quickly receive input regarding stakeholders' insights, centralize 
and coordinate the flow of information, monitor the situation, and reach rapid census on relief efforts that transcend geographical boundaries. EOCs are found in many other countries, at various government levels, as well as in private organizations. Effective EOC management and operations require having written policies and procedures in place prior to an emergency (FEMA-EMI, 2010). In general, an EOC must have procedures and policies in place with regard to 1) communication, 2) life support, 3) equipment and supplies, and 4) document and research retention.

In 2011, the United World Tourism Organization (UNWTO) established a new initiative aimed at integrating emergency management and tourism resources, in an attempt to secure traveler safety as well as increase the effectiveness of existing emergency management measures (UNWTO, 2011). For EOCs, who are in charge of emergency planning, collaboration with the tourism industry provides them with more tools and responses for disaster response, and building community resilience. The tourism industry also can benefit from such partnerships. Tourists have been identified as a major target group for emergency planning, as they are away from home and have limited local knowledge related to crisis preparedness and evacuation. Most tourism facilities, such as hotels and attractions, are located in areas prone to natural disasters. Thus, a formal and functional relationship with emergency management leaders such as the EOC can help tourism professionals better prepare for disasters and protect tourists and their businesses.

Past studies have also advocated that local DMOs should have a representative serve on their local EOC as a liaison for the tourism industry. By doing so, DMOs can relay information to the tourism industry about policies and regulations that are enacted (e.g., price gauging law) and offer assistance in emergency planning (Cahyanto \& Pennington-Gray, 2015). Although this is not a new issue in tourism research, very few 
studies have approached this concept from a tourism policy perspective and provided insights into the area of emergency management and tourism (Morakabati, Page, \& Fletcher, 2017). Similarly, very few studies have investigated the particular PPP in terms of the partnership between EOCs and the tourism industry.

Based on the aforesaid discussion, this study is framed by the following three interrelated questions.

1. How does the public sector view their disaster-related partnerships with the tourism industry?

2. From public sector's perspective, what role should the tourism industry play in their partnership in disaster management?

3. What challenges exist in establishing public-private partnerships with the tourism industry in disaster management?

\section{Methods}

\subsection{Research Design}

This study is grounded in the social constructivism paradigm, which postulates that multiple realities exist where participants create understanding and knowledge, and is of intrinsic value to the research process (Stebbins, 2011). More specifically, this study included group discussions and individual follow-up interviews. By bringing together key personnel in both the public and private sectors, the group discussion is 'more valuable than any representative sample' and is able to 'revise or solidify the researcher's image of the reality of a social setting' (Frey \& Fontana, 1991, p. 177). The follow-up interviews allow the researchers to confirm and/or clarify the major themes that emerged in the discussion. Additionally, this study focused on the context of 
hurricanes and explored how the PPP between EOCs and the tourism industry is viewed by different parties regarding co-managing hurricane disasters.

\subsection{Data collection and Analysis}

The data gathered for this study were obtained from a group discussion and individual follow-up interviews. Regarding the group discussion, participants were comprised of 71 EOC personnel at the county or city level throughout the U.S. Forty-six of them were from south-eastern states, 20 resided in north-eastern states, and three were from other areas (U.S. Virgin Islands, Puerto Rico) (See Table 1). Four facilitators, including three DMO personnel and a hotel safety manager, also participated in the discussion.

The discussion took place in a 2-hour session at a national hurricane conference. During the session, participants were first asked to respond to three key questions through the PollEverywhere app, which allows them to remain anonymous if desired. The facilitators from the tourism industry (i.e., DMOs, hotels) then led the discussion by sharing their experiences in working with their respective EOCs in the past hurricane season. After that, the participants' responses to the key questions were collected and displayed on the main screen, which prompted further discussion around the topic. The section concluded by debriefing and asking participants to provide suggestions on how to improve partnerships between EOCs and the tourism industry. Lastly, the three key questions featured in the section were: 1) How would you rate the partnership between your local EOC and your local tourism industry?; 2) What role should the tourism industry play in the event of a hurricane?; and 3) What challenges do you see that may hinder partnerships between your EOC and your local tourism industry?

To further contemporize the results of the group discussion, ten individual follow-up interviews were conducted. Among the interviewees, six of them were from national-level EOCs, three were from city-level ECOs, and five represented state-level 
EOCs. Seven of them were located in south-eastern states, two of them resided in northern states, and one was from a U.S. territory (See Table 1). The interviews aided in clarifying and verifying perspectives that emerged during the discussion. The participants were chosen based on the size of their jurisdiction and locations. The interview questions were developed based on the group discussion. On average, the interview took forty-five minutes. Data was saturated on the $9^{\text {th }}$ interviewee, which suggested that there would be no need for conducting further interviews (Creswell, 2014).

[Table 1 near here]

Data analysis included transcribing the data and validating the transcription (Miles \& Huberman, 1994). Complete verbatim transcripts of the PoolEverywhere responses, group discussion, and follow-up interviews were conducted (Veal, 2017). Thematic analysis was utilized to analyze the data and identify major themes. Data were organized analysed by using the software NVivo. The themes were then clarified and discussed by the researchers. Lastly, results from the group discussion and follow-up interviews were triangulated to ensure that the study captured the topic thoroughly.

\section{Results}

\subsection{How does the public sector view their disaster-related partnerships with the tourism industry?}

To gain a better understanding of the current status of the partnerships between EOCs and the tourism industry, the respondents were first asked to indicate if they were satisfied with the current collaboration. As shown in Figure 1, more than a quarter (27\%) of the respondents opined that their EOCs had above average to excellent partnerships with the tourism industry, such as with accommodations, Convention Visitors Bureaus, and transportation. Around one-fifth (21\%) of them, however, 
indicated that their EOCs had below average or poor partnerships with their local tourism industry. Interestingly, only around one third (36\%) of the respondents indicated that they were aware of the current partnerships with the local tourism industry. Among these participants who reported knowledge about the partnerships, the average satisfaction score is $3.2(\mathrm{SD}=1.2)$, suggesting an average level of satisfaction with the current working relationship with the tourism industry.

Overall, the results of the poll indicated that most respondents were relatively discontent with their current partnerships between their EOC and the tourism industry. Only a few participants were satisfied with their partnership, and those that reported being satisfied are more likely to be in large cities and jurisdictions. The dissatisfaction likely results from the fact that some respondents "were unfamiliar with the nature and scope of partnerships with their local tourism industry," and/or "were new in their position and have not had time to examine the partnerships."

[Figure 1 near here]

\subsection{The role of the tourism industry in disaster management}

The second research question focused on how the EOC viewed the roles of the tourism industry in the event of hurricanes. The results suggested the following themes: 1) information and communication liaison, 2) logistic and life support partners, 3) equipment and supplies providers, and 4) philanthropic effort liaison.

\subsubsection{Information and communication liaison}

One of the most commonly mentioned roles of the tourism industry during hurricanes is the communication arm of the EOC in relation to visitors. As one participant addressed, 'tourism should be integrated within the state EOC as another partner to disseminate 
information.' The importance of integrating tourism and EOC is to 'assist with providing visitors with situation awareness and safety instruction,' and 'get the message out to the partners.' To increase the effectiveness of risk and crisis communication, most participants expected to have a tourism representative on board and to deliver essential safety information to the visitors. During hurricane events, for example, information such as airport closures, evacuation orders for visitors, and current conditions, are all essential in risk communication and should be effectively conveyed to visitors.

\subsubsection{Logistic and life support partners}

The second theme that emerged from both the group discussion and follow-up interviews revolved around logistic and life supply partners for the EOCs. The tourism industry often has resources that can help EOCs function effectively. Secondary EOC command centers are often located in hotels or resorts because they tend to have better facilities, including large conference rooms, power generators, sleeping arrangements, food service, and sanitary facilities such as showers and laundry facilities for personnel (Dobie, Schneider, Kesgin, \& Lagiewski, 2018). Most participants underscored the importance of hotels in a crisis situation because they can 'provide shelters for first responders,' offer 'temporary sheltering for displaced residents,' 'provide space as a backup EOC if the central EOC is compromised,' and even 'assist EOC and response team members with any accommodation and meal preparations.'

\subsubsection{Equipment and supplies providers}

Equipment and supplies are always needed in emergency situations, and the respondents also mentioned how the tourism industry could satisfy such needs. The tourism industry is comprised of multiple businesses, including transportation, accommodations, and 
restaurants. Additionally, tourism businesses often have extra equipment such as power generators, spare parts inventory for backup lighting, and communication equipment. Large resorts may also have better-updated communication equipment such as satellite phones. All these resources are essential in emergency situations. Noting the importance of such equipment and supplies, the participants appreciated the tourism business' contributions by offering equipment and supplies during emergencies. To guarantee such assistance, some participants further suggested that 'an MOU needs to be in place between the business and the EOC,' so that they can better manage different difficult situations.

\subsubsection{Philanthropic efforts liaison}

One interesting theme that emerged from the discussion was how the tourism industry could act as a liaison to facilitate community philanthropic efforts during recovery. Because the main responsibility of DMOs is to market a destination, the industry always has useful contacts in place. Some tourism industry partners can act as a liaison for relief efforts such as coordinating the collection of donations or necessities which are needed by the localities during a recovery period (fuel, food, plywood). The industry can also coordinate donation efforts from past visitors or organize philanthropic efforts to support recovery efforts implemented by the EOC and the local government. Additionally, as they have access to broader audiences, hotels and resorts can relay information and recovery needs on their media platforms to their vendors, past visitors, and other tourism stakeholders to help accelerate recovery.

\subsection{Major Challenges}

Lastly, this study identified the major challenges faced by EOCs and the tourism industry regarding their co-management partnerships. The results revealed the following 
themes: local political discourse, financial support, and communication.

\subsubsection{Local political discourse}

The most commonly cited challenge to the partnership was the dynamic of local political discourse, which, according to some participants, was mainly due to the distrust between local elected officials and the tourism business community in their

jurisdiction. On some occasions, the distrust issues may thwart the forming of partnerships and collaborations. In addition, there were concerns about the delivery of promises. As one participant pointed out, they worry about 'how to ensure each party would do what they said they would do once they are capable after the event.' Even though some participants were aware of the Memorandum of Agreement (MOA) between EOCs and local hotels or other tourism providers, concerns still exist regarding how the agreements can be enforced to ensure that services can be delivered during crises.

\subsubsection{Financial support}

Financial concern is another factor that can impede forming and maintaining partnerships between EOCs and the tourism industry. Because emergency preparedness funding is typically very stringent and, in some jurisdictions, comes from several accounts, participants said that there is often confusion in terms of "who pays for what service and when they get paid.' In many situations, the use of certain accounts that are designated for emergency preparedness and response is very restricted and can only be used for a very specific purpose. As such, when the situation arises in which spending needs to be reimbursed for items such as special meals, it can result in a change in terms of which account should pay, which can disrupt the typically inflexible funding structures. 
The participants also acknowledged challenges associated with FEMA's Transitional Sheltering Assistance (TSA). Under TSA, disaster survivors may stay in a hotel or motel for a limited period of time and have the cost of the room and taxes covered by FEMA. The state and the EOCs may request that FEMA authorize the use of TSA for a declared disaster in a specific location. The standard procedure for FEMA to authorize and fund direct payments to participating hotels and motels that are designated as transitional shelters. In many cases, EOCs works with local hotels during the process, but issues can be raised in two ways. First, in some communities, the only available rooms are in resorts, which tend to be well designed as a shelter; however, resorts have difficulty in getting reimbursed from FEMA because the word resort that has a connotation of luxury. The second issue is that because FEMA does not require evacuees to notify the agency when they check out of hotels, hotels can continue to bill FEMA for unoccupied rooms. Additionally, because of this lack of control, the agency has no information regarding the auditing of room charges (DHS, 2019).

\subsubsection{Communication}

Lastly, the issue of communication evinced during the discussion and interviews. Participants mentioned that from the EOC and government standpoint, they need to be cautious and often will not release any information until decisions are made, or the evacuation timeline is established. Therefore, the private sector, including the tourism industry, is often left in the dark during the process. However, the private sector bears the responsibility of ensuring guest safety and is in need of crisis and risk information in a timely manner. The inconsistency, therefore, has created a conflicting situation that requires additional communication efforts. Furthermore, some participants noted that sometimes the recommended responses can have adverse economic impacts on the private sector. As a result, the tourism industry, along with other entities in the tourism 
sector, needs to balance their social responsibility of ensuring public safety with their financial responsibility for generating revenue.

\section{Discussion}

A functional and reliable adaptive co-management relationship between the EOC and the tourism industry not only offers a prominent example of PPPs but also is a requisite for resilient communities and in the face of disasters such as hurricanes (Stewart, Kolluru, \& Smith, 2009). By exploring the perceptions and viewpoints from the public sector, this study examined the PPP through the lenses of adaptive co-management. Mainly, this study revealed the level of satisfaction among EOC personnel regarding their current partnerships with the tourism industry nationwide, explored their expectations of the tourism industry, and identified the major challenges to the existing PPP. The major findings are summarized and presented in Figure 2.

[Figure 2 near here]

The ACM framework suggests that communication and shared responsibility are fundamental to establishing effective co-management partnerships. Consistently, the results showed that there is a lack of communication between different entities and an absence of a clear understanding of each other's roles and responsibilities at all phases in disaster management. These reported issues not only are parallel with the findings of past studies (Auzzi, Haigh, \& Amaratungga, 2014), but also partly account for the lack of satisfaction from EOC personnel regarding the current PPPs with the tourism industry. Social learning also becomes essential in the current study, as it can enable stakeholders to interact, collaborate, and learn from each other. As Islam et al (2018) suggested, an adaptive learning process is especially suitable for a context of changing and uncertainty. Therefore, improving communication between these entities and 
facilitating the social learning process would be beneficial for establishing effective PPPs in disaster management.

There are also financial concerns, which mainly arise from the ambiguity of financial policies, regulations, and reimbursement procedures between agencies. These agencies also temper their level of effort according to the perceived fairness of the distribution of responsibility (Al Arkoubi \& Davis, 2013). The severity of these concerns and the means of resolving them fluctuate, in part due to the uncertainty and complexity of the tasks performed and the mixture of partners' characteristics and organizational dynamics.

In complex, indeterminate environments such as a disaster area, the ACM framework highlights the importance of having a flexible, adaptive coordination and control mechanisms (Islam et al., 2019). While formal mechanisms such as contracts or MOAs between the public and the tourism industry may work well in partnerships for critical infrastructure and post-disaster recovery, these arrangements may fail to respond to changing and unanticipated conditions. Over-reliance on formal hierarchical controls and coordination mechanisms may involve prohibitive monitoring, enforcement, and other transaction costs, which can render the partnerships untenable. A MOA or contract may cause or require government agencies to reach out to their partnered tourism companies first. However, the high time-sensitivity of providing food and shelter during a disaster will lead to the abrogation of these deals if the tourism partner is not ready to produce quickly upon request. Likewise, the absence of responsible parties with established relationships on both sides of the PPP at the time of the disaster can lead to unexpected delays and failures.

Indeed, according to studies related to ACM, PPPs by nature are reliant on relationships (Natcher, Davis, \& Hickey, 2005). ACM is not a fixed state, but rather, a 
process occurring along a continuum (Carlsson \& Berkes, 2005). Thus, emphasis should be displayed on managing human relationships and understanding the underlying conditions by which arrangements will be performed (Natcher et al., 2005). Overreliance on formal hierarchical controls and coordination mechanisms may result in prohibitive monitoring, enforcement, and other transaction costs, all of which can render the partnerships untenable. For PPPs involving the tourism industry, there is a need to consider linkages, resources, skills and knowledge, technology, and authority of the organization (Pennington-Gray et al., 2014).

It is critical for those engaged in these types of collaborations to share a commitment to the greater goal, the continuity of the community. It is essential to identify common issues related to disaster preparedness, but it is also important for collaborators to identify how disaster preparedness is part of broader community resilience building. Through partnerships with the tourism industry, local EOCs can foster a central community foundation that functions as a repository for donated assistance funds and goods for rapid distribution into the community when disasters strike. The tourism industry, with its network, can assist reaching donors from outside the community through their communication channels.

Additionally, the findings of the study noted that distrust is a major issue affecting collaboration. This not only hinders the formation of new PPPs but also threatens the efficacy and eventual effectiveness of existing agreements. Many factors may lead to distrust, such as inequality, past conflicts, and competing interests. To remedy the situation, Mojtahedi and Oo (2017) argued that stakeholder attributes, including power, legitimacy, and urgency, should be taken into account to develop a proactive approach to disaster management. 
Strong leadership is also pivotal, as it often correlates with higher levels of trust and effectiveness (Gunton \& Day, 2003). Due to competing interests, business cycles, and disparate incentives, it is challenging to maintain a positive co-managing relationship between the public and private sectors. Therefore, strategic thinking is required. There are several expected outcomes of co-management, such as efficiency of decision-making, increased capacity, and legitimation of action, all of which should, therefore, be set as the primary goals of the PPPs and collaborations in the current context (Plummer \& Fitzgibbon, 2004).

This study is not without limitations, as the data for this study were collected during a session on hurricane preparedness at a conference. The high number of participants and the fixed amount of allotted time might hinder the depth of the data. Ensuring that all attendees spoke was challenging as there were over eighty people in attendance. Group dynamics might also constrain the findings. The use of the PoolEverywhere app did, however, allow all participants to express their answers to the questions without constraint, even if some of the statements were not explored immediately due to time constraints. This goodwill can be quantified and serve as an intrinsic asset on the company's balance sheet (Torres, Marshall, \& Sydnor, 2019). As such, it is recommended that future studies utilize a quantitative approach to validate the topics that emerged in this study. With a clearer view of the incentives and potential advantages of partnering with the public sector for disaster response, managers will be able to more effectively persuade owners and shareholders to participate in disasterrelated PPPs.

\section{Future Research and Conclusion}

From a theoretical perspective, this paper contributed to the tourism crisis management and disaster management literature by examining the public sector's views on 
partnering with the tourism industry in disaster management. This study also extended the application of the ACM framework to tourism disaster management, as it has historically been used primarily for natural resource management. From a practical perspective, this study not only addressed the importance of establishing PPP in disaster management, but also stressed the significance of communication and collaboration, social learning, shared responsibility, community resilience. These are key principles of the ACM framework, but need to be strengthened in the current context.

Further, this study provides three critical directions for future studies. Firstly, considering the influence of local political discourse on PPPs, future studies should explore how an ACM-based approach may improve the trust issues and contribute to a strong co-management relationship in disaster management? Secondly, social learning is a crucial feature of ACM, which helps to form a shared and common understanding among stakeholders. In light of this, future studies can investigate how social learning may occur in the collaboration between the public sector and private tourism organizations in responding to disasters, and identify what platforms would be available to co-produce and share the knowledge related to disaster management. Thirdly, ACM aims at enhancing the adaptive resilience of the community. Thus, it is pivotal to examine factors that motivate tourism businesses of all sizes to partner with the public sector to build disaster resilience in different types of communities (e.g., rural vs. urban).

Lastly, co-managing disasters between public and private entities is complex due to competing motivational factors. However, a shared interest in community continuity following a disaster should serve a foundation for co-managing disasters. After all, even though the private sector primarily functions according to its profit motive, the longterm survival of any business within a disaster area is dependent upon an efficient 
response and recovery effort. The revenue secured through ACM can serve as both a revenue bridge from pre-disaster to post-disaster financial stability, but also aids private organizations in efforts to garner goodwill within the community, which in turn enhances the adaptive resilience of the community. 


\section{References}

Al Arkoubi, K., \& Davis, E. (2013). Building sustainable organizational social capital: The global leadership challenge. Global Journal of Management and Business Research.

Armitage, D., Berkes, F., \& Doubleday, N. (Eds.) (2007). Adaptive co-management: collaboration, learning, and multi-level governance. Vancouver, CA. University of British Columbia Press.

Auzzir, Haigh, \& Amaratunga, D. (2014). Public-private partnerships (PPP) in disaster management in developing countries: a conceptual framework. Procedia Economics and Finance 18, 807-814.

Bajracharya, B., Hastings, P., Childs, I.R.W. \& McNamee, P. (2012), Public-Private Partnership in Disaster Management: A Case Study of the Gold Coast. Australian Journal of Emergency Management, 27(3), 27-33.

Berkes, F. (1997). New and not-so-new directions in the use of the commons: Comanagement. The Common Property Resource Digest, 42, 5-7.

Berkes, F. (2002). Cross-scale institutional linkages: perspectives from the bottom up. In: Ostrom, E., Dietz, T., Dolsak, N., Stern, P.C., Stonich, S., Weber, E.U.(Eds.). The Drama of the Commons (pp.293-321). Washington D.C: National Academy Press,

Berkes, F. (2007). Adaptive co-management and complexity: Exploring the many faces of co-management. In D. Armitage, F. Berkes, \& N. Doubleday (Eds.), Adaptive co-management: Collaboration, learning, and multi-level governance (pp. 1937). Vancouver, Canada: University of British Columbia Press

Berkes, F. (2009). Evolution of co-management: Role of knowledge generation, bridging organizations, and social learning. Journal of Environmental Management, 90, 1692-1702. 
Berkes, F., George, P., \& Preston, R. (1991). Co-management. Alternatives, 18(2), $12-$ 18.

Borrini-Feyerabend, G. (1996). Collaborative management of protected areas: Tailoring the approach to the context IUCN, Gland, Switzerland.

Borrini-Feyerabend, G., Farvar, M.T., Nguinguiri, J.C., \& Ndangang, V. (2000). Comanagement of natural resources: Organizing Negotiation and Learning by Doing. Heidelberg, Germany: Kasparek,

Boyer, E.J. (2019). Unpacking the influence of public-private partnerships on disaster resilience: a comparison of expert perspectives. Annals of Public and Cooperative Economics, 90(2), 329-351.

Bramwell, B., \& Lane, B. (2000). Collaboration and partnerships in tourism planning. Tourism collaboration and partnerships: Politics, practice and sustainability, 2, 1-19.

Buse, Kent \& Walt, G. (2000). Global public-private partnerships: pt. 1. A new development in health? Bulletin of the World Health Organization: the International Journal of Public Health, 78(4), 549-561.

Cahyanto, I., \& Pennington-Gray, L. (2015). Communicating Hurricane Evacuation to Tourists: Gender, Past Experience with Hurricanes and Place of Residence. Journal of Travel Research, 54(3), 329-343.

Cahyanto, I., Pennington-Gray, L., Thapa, B., Srinivasan, S., Villegas, J., Matyas, C., Kiousis, S. (2014). An empirical evaluation of the determinants of tourist's hurricane evacuation decision making. Journal of Destination Management and Marketing, 2, 253-265.

Carlsson, L. \& Berkes, F. (2005). Co-management: concepts and methodological implications. Journal of Environmental Management, 75, 65-76. 
Chandra, A., Moen, S., \& Sellers, C. (2016). What Role Does the Private Sector Have in Supporting Disaster Recovery, and What Challenges Does It Face in Doing So?. Santa Monica, CA: RAND Corporation.

Chen, J., Chen, T.H.Y., Vertinsky, I., Yumagulova, L., \& Park, C. (2013). Publicprivate partnerships for the development of disaster resilient communities. Journal of Contingencies and Crisis Management, 21(3), 130-143.

Christoplos, I. (2003), 'Actors in Risk', in Pelling, M. (ed.), Natural Disasters and Development in Globalizing World (pp. 95-109). New York, NY: Routledge.

Creswell, J.W. (2014). Research design: Qualitative, quantitative, and mixed methods approaches. CA: Sage Publications.

Curnin, S., \& O’Hara, D. (2019). Nonprofit and public sector interorganizational collaboration in disaster recovery: Lessons from the field. Nonprofit Management \& Leadership, 30(2), 277-297.

De Lacy, T., Battig, M., Moore, S., \& Noakes, S. (2002). Public/private partnerships for sustainable tourism. Gold Coast: CRC for Sustainable Tourism.

Department Homeland Security (DHS) (2018). Disaster declarations by years. Available at https://www.fema.gov/disasters/year

Department of Homeland Security (DHS) (2019). Additional controls needed to better manage FEMA's Transitional Sheltering Assistance program OIG-19-37. DHS Office of Inspector General. Washington, D.C: U.S. Department of Homeland Security.

Dobie, S., Schneider, J., Kesgin, M., \& Lagiewski, R. (2018). Hotels as Critical Hubs for Destination Disaster Resilience: An Analysis of Hotel Corporations' CSR Activities Supporting Disaster Relief and Resilience. Infrastructures, 3(4), 46. 
Federal Emergency Management Agency - Emergency Management Institute (FEMAEMI) (2010). IS275: The EOC's role in community preparedness, response, and recovery activities. Federal Emergency Management Agency - Emergency Management Institute.

Federal Emergency Management Agency (FEMA) (2011). A whole community approach to emergency management: principles, themes, and pathways for action. FDOC 104-008. FEMA.

Frey, J. H., \& Fontana, A. (1991). The group interview in social research. The Social Science Journal, 28(2), 175-187.

Frohlich, T. C. (2018). From Elena to Katrina: these are the costliest hurricanes to ever hit the US. USA Today. September 12. Available at https://www.usatoday.com/story/money/2018/09/12/most-destructivehurricanes-of-all-time/36697269/

Gabler, C.B., Richey, R.G., \& Stewart, G.T. (2017). Disaster resilience through publicprivate short-term collaboration. Journal of Business Logistics, 38, 130-144.

Graci, S. (2013). Collaboration and partnership development for sustainable tourism. Tourism Geographies, 15(1), 25-42.

Gray, B. (1989). Collaborating: Finding common ground for multiparty problems. San Francisco, CA: Jossey-Bass.

Gunton, T.I., \& Day, J. C. (2003). The theory and practice of collaborative planning in resource and environmental management. Environments, 31(2), 5-19.

Halim, H. S. (2016). Co-management: Valuating Social Communication of Sustainable Coastal Tourism, in Indonesia. International Journal of Marine Science, 6(46), $1-10$ 
Hayllar, M.R. \& Wettenhall, R. (2010), 'Public-Private Partnerships: Promises, Politics and Pitfalls', Australian Journal of Public Administration, 69(1), 1-7.

Ingles, A. W., Musch, A., \& Qwist-Hoffmann, H. (1999). The participatory process for supporting collaborative management of natural resources: An overview. Rome: Food and Agriculture Organization of the United Nations.

Islam, W., Ruhanen, L. \& Ritchie, B.W. (2019). Governance for nature-based tourism in protected areas: Investigating the application of adaptive co-management approach. Journal of Sustainable Tourism, 26 (11), 1890-1908. DOI:

$10.1080 / 09669582.2018 .1526291$

Islam, W., Ruhanen, L. \& Ritchie, B.W. (2018). Exploring social learning as a contributor to destination governance? Tourism Recreation Research, 1-11. DOI:10.1080/02508281.2017.1421294

Islam, W., Ruhanen, L. \& Ritchie, B.W. (2017). Adaptive co-management: A novel approach to nature-based tourism destination governance? Journal of Hospitality and Tourism Management, 1-10 doi.org/10.1016/j.jhtm.2017.10.009

Jaireth, H., \& Borrini, G. (2007). Sharing power: learning-by-doing in co-management of natural resources throughout the world. London, UK: Routledge.

Jiang, Y. \& Ritchie, B. (2017). Disaster collaboration in tourism: motives, impediments and success factors. Journal of Hospitality and Tourism Management, 31, 70-82.

Kapucu, N. (2006). Interagency communication networks during emergencies boundary spanners in multiagency coordination. American Review of Public Administration, 36, 207-225.

Kofinas, G. P. (2009). Adaptive co-management in social-ecological governance. In Principles of ecosystem stewardship (pp. 77-101). New York, NY: Springer. 
Lee, Y., Watanabe, K., \& Li, W. S. (2019). Public Private Partnership Operational Model-A Conceptual Study on Implementing Scientific-Evidence-Based Integrated Risk Management at Regional Level. Journal of Disaster Research, 14(4), 667-677.

May, P.J. \& William, W. (1986). Disaster policy implementation: managing programs under shared governance. New York, NY: Plenum.

Miles, M.B., \& Huberman, A.M. (1994). Qualitative data analysis (2nd ed.). Thousand Oaks, CA: Sage.

Mitchell, B. (1997). Resource and environmental management. Essex: Longman.

Mitchell, J.K. (2006). The primary of partnership: Scoping a new national disaster recovery policy. The Annals of the American Academy of Political and Social Science, 604(1), 228-255.

Mojtahedi, M., \& Oo, B. L. (2017). Critical attributes for proactive engagement of stakeholders in disaster risk management. International Journal of Disaster Risk Reduction, 21, 35-43.

Morakabati, Y., Page, S. J., \& Fletcher, J. (2017). Emergency management and tourism stakeholder responses to crises: A global survey. Journal of travel research, 56(3), 299-316.

Natcher, D., Davis, S., \& Hickey, C. (2005). Co-management: Managing relationships, not resources. Human Organization, 64(3), 240-250.

National Research Council (NRC) (2011). Building Community Disaster Resilience Through Private-Public Collaboration, National Research Council (US), Committee on Private-Public Sector Collaboration to Enhance Community Disaster Resilience. Washington, DC.: National Academies Press. 
Nguyen, D., Imamura, F., \& Iuchi, K. (2017) Public-private collaboration for disaster risk management: a case study of hotels in Matsushima, Japan. Tourism Management, 61, 129-140.

Pennington-Gray, L., Schroeder, A., \& Gale, T. (2014). Co-management as a framework for the development of a tourism area response network in the rural community of Curanipe, Maule Region, Chile. Tourism Planning \& Development, 11(3), 292-304.

Pinkerton, E. (Ed). (1989). Co-operative management of local fisheries. Vancouver, Canada: University of British Columbia Press.

Plummer, R. \& FitzGibbon, J. (2004). Some observations on the terminology in cooperative environmental management. Journal of Environmental Management, $70,63-72$.

Plummer, R., \& Armitage, D. (2007). A resilience-based framework for evaluating adaptive co-management: linking ecology, economics and society in a complex world. Ecological Economics, 61(1), 62-74.

Plummer, R., \& Fitzgibbon, J. (2004). Co-management of natural resource: a proposed framework. Environmental Management, 33(6), 876-885.

RECIPE. (2011). Manual for the Protection of Critical Infrastructure, NO - Critical Infrastructure Protection (CIP) Policies in Europe, Delft.

Ritchie, B. (2004). Chaos, crises and disasters: A strategic approach to crisis management in the tourism industry. Tourism Management, 25, 669-683.

Ritchie, B., \& Campiranon, K. (Eds.) (2015). Tourism crisis and disaster management in the Asia-Pacific. Oxfordshire: Cabi.

Selin, S., \& Chavez, D. (1995). Developing a collaborative model for environmental planning and management. Environmental Management, 19, 189-195. 
Shoeb-Ur-Rahman, M., Simmons, D. G., Shone, M., \& Ratna, N. (2019). Comanagement of Capitals for Community Wellbeing and Sustainable Tourism Development: A Conceptual Framework. Tourism Planning \& Development, DOI: $10.1080 / 21568316.2019 .1600161$

Siemiatycki, M. (2011). Urban transportation public-private partnerships: drivers of uneven development?. Environment and Planning A, 43, 1707-1722.

Singleton, S. (1998). Constructing cooperation: the evolution of institutions of comanagement. Ann Arbor, MI: University of Michigan Press.

Stankey, G. H., McCool, S. F., Clark, R. N., \& Brown, P. J. (1999). Institutional and organizational challenges to managing natural resources for recreation: A social learning model. In E. L. Jackson \& T. L. Burton (Eds.), Leisure studies: Prospects for the 21st century (pp. 435-450). State College, PA: Venture.

Stebbins, R.A. (2001). Exploratory research in the social sciences. Thousand Oaks, CA: Sage Publications, Inc.

Stewart, G.T., Kolluru, R., \& Smith, M. (2009). Leveraging Public-Private Partnerships to Improve Community Resilience in Times of Disaster. International Journal of Physical Distribution and Logistics Management 39(5), 343-64.

Torres, A. P., Marshall, M. I., \& Sydnor, S. (2019). Does social capital pay off? The case of small business resilience after Hurricane Katrina. Journal of Contingencies and Crisis Management, 27(2), 168-181.

UNISDR (2008). Private Sector Activities in Disaster Risk Reduction, Good Practices and Lessons Learned. Available at http://www.unisdr.org/we/inform/publications/7519 
UNWTO (2011) Integrating tourism and emergency management. Available at https://media.unwto.org/news/2011-10-07/integrating-tourism-and-emergency$\underline{\text { management }}$

Van den Hurk, M., \& Siemiatycki, M. (2018). Public-private partnerships and the design process: Consequences for architects and city building. International Journal of Urban and Regional Research, 42(4), 704-722.

Veal, A.J. (2017). Research methods for leisure and tourism: A practical guide. England, UK: Pearson.

Warner, J.F. (2006). More sustainable participation? Multi-stakeholder platforms for integrated catchment management. Water Resources Development, 22(1), 1535.doi: $10.1080 / 07900620500404992$

Wilson, E., Nielsen, N., \& Buultjens, J. (2009). From lessees to partners: exploring tourism public-private partnerships within the New South Wales national parks and wildlife service. Journal of Sustainable Tourism, 17(2), 269-285.

Wondolleck, J. M., \& Yaffee, S. L. (2000). Making collaboration work: Lessons from innovation in natural resource management. Washington, DC: Island Press.

World Bank (1999). Report from the International Workshop on Community-based Natural Resource Management (CBNRM), Washington, DC, May 11-14, 1998. 
Table 1. Sample Profile

\begin{tabular}{llllll}
\hline Jurisdiction & Discussion & Interview & Location & Number & Interview \\
\hline Counties /Parish & 45 & 6 & Southeast States & 46 & 7 \\
City & 19 & 3 & Northeast States & 20 & 2 \\
State & 5 & 1 & Other & 3 & 1 \\
Total & 69 & 10 & Total & 69 & 10 \\
participants & & & Participants & & \\
\end{tabular}


Figure 1. Satisfaction level on partnership with the tourism industry

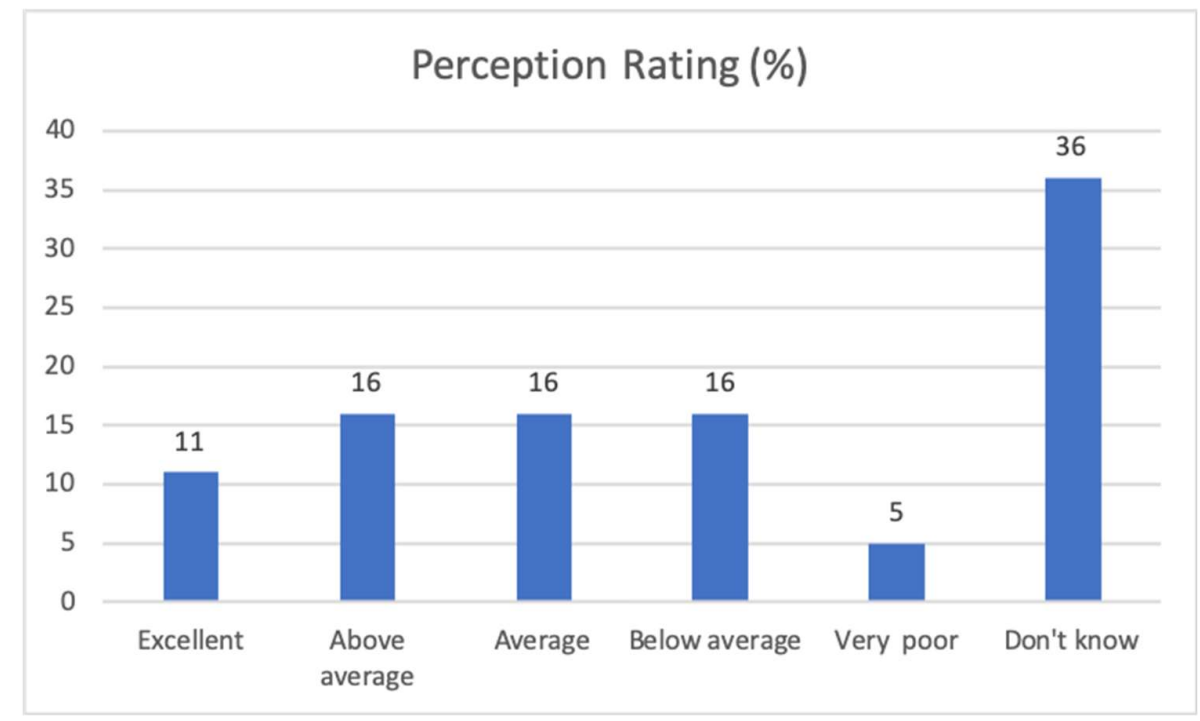


Figure 2. Results of the Thematic Analyses

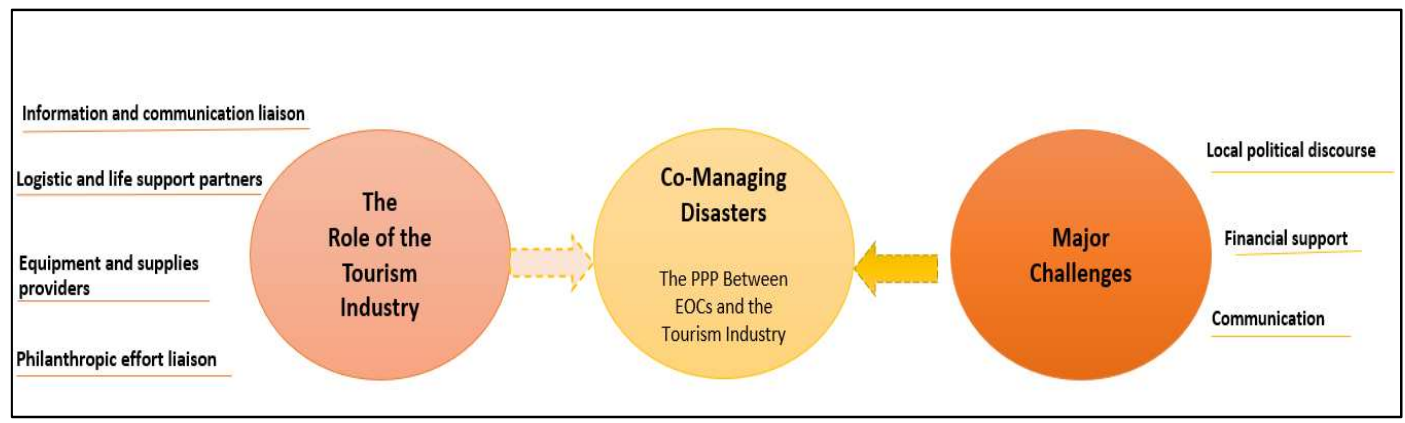

